* Artículos 



\title{
J. J. Bachofen y el retorno de las Madres
}

\author{
Annunziata Rossi
}

El presente artículo trata sobre lo expuesto por Johann Jakob Bachofen en su obra Matriarcado con respecto al sistema ginecocrático, imperante en las primeras sociedades prehistóricas; su desarrollo a lo largo de la historia y su declinación ante el advenimiento del patriarcado como sistema regulador de la sociedad vigente aún en la actualidad. Asimismo se habla de la transición de uno a otro sistema y de su alternancia a través de la comparación establecida por Bachofen entre el matriarcado y el patriarcado.

Palabras Clave: matriarcado, Bachofen, cultura ginecocrática.

This article addresses different topics covered on Das Mutterrecht by J. Jakob Bachofen about the gynaecocratic system that supposedly ruled on early prehistoric societies: its historic development and its decline before the ascension of patriarchy as the main social controller system, as seen today. Similarly, this paper approaches the transition between both social systems and their alternation, through the distinction between matriarchy and patriarchy, as drawn by Bachofen.

KEY WORDS: matriarchy, Bachofen, gynaecocratic culture. 



\section{Annunziata Rossi}

Instituto de Investigaciones Filológicas, Universidad Nacional Autónoma de México

\section{J. J. Bachofen y el retorno de las Madres}

Primero entre todos los dioses, venero en mi plegaria a Gea, vidente de los tiempos primordiales.

Esquilo, "Las Euménides", Orestíada

Johann Jakob Bachofen (1815-1887), perteneciente a una familia aristocrática y acaudalada de Basilea, fue profesor de Derecho Romano en las universidades de Berlín y Basilea. Gozó de gran estimación en el ambiente académico hasta que desvió su atención del Derecho Romano hacia la prehistoria, y descubrió que en los albores de la humanidad había imperado la ginecocracia, el reino de las madres y el derecho materno.

En un estupendo ensayo de 1936 sobre Bachofen, Walter Benjamin afirma que el pensador de Basilea fue el pionero de los estudios sobre la mujer, el descubridor de la ginecocracia, un "profeta" del retorno de las Madres en la segunda mitad del siglo XIX. "Como un volcán, cuyo potente cono ha sido provocado por fuerzas subterráneas, que desde entonces han dormitado mucho tiempo, la obra de Bachofen ha representado durante medio siglo una masa imponente, y sin embargo apagada" (Benjamin, Obras, 223). Asimismo destaca que: 
Mucho antes de que los símbolos arcaicos, el culto y la magia mortuorios y los ritos de la tierra hubieran llamado la atención no sólo de los exploradores de la mentalidad primitiva, sino también de los psicólogos freudianos y de la gente culta en general, un sabio suizo [J. J. Bachofen] había elaborado una interpretación de la prehistoria que rechazaba todo cuanto el sentido común del siglo XIX había imaginado sobre los orígenes de la religión y de la sociedad. [...] Con el paso del tiempo, esta interpretación, que pone en primer plano las fuerzas irracionales en su significado cívico y metafísico, resultó ser muy interesante para los teóricos fascistas; pero también atrajo pensadores marxistas por su sugestiva evocación de una primera forma de sociedad comunista justo en los comienzos de la historia [...] (223).

Las "fuerzas irracionales" de las que habla Benjamin emergieron paulatinamente en elúltimo decenio del siglo XIX e irradiaron en varias direcciones, alimentando al marxismo, al psicoanálisis y al movimiento feminista, para confluir en los "Cósmicos de Munich" y en la Bachofen-Renaissance de la Alemania de los primeros decenios del sigloxx. Desembocaron, en fin, en los “teóricos fascistas" alemanes. Para estudiar ese estadio originario de civilización Bachofen recurrió a un material enorme, heterogéneo, impresionante: símbolos y mitos, documentos históricos, literarios y artísticos (la filología, sin interés por las obras de arte, afirma el estudioso, queda como un "esqueleto sin vida"), y también a la etnología, la antropología y la arqueología, citando de manera escrupulosa (y no siempre exacta) sus fuentes. El resultado de su incansable investigación fue la obra monumental Matriarcado (1861), de más de mil páginas, con un subtítulo que precisa mejor el tema: Investigación sobre la ginecocracia del mundo antiguo en sus aspectos religiosos y jurídicos. $^{1}$

${ }^{1}$ En esos años, precisamente en 1859, habían salido a la luz otros dos libros revolucionarios, El origen de las especies, de Darwin, y La introducción a la crítica de la economía política, de Marx. 
El descubrimiento de la ginecocracia en los albores de la humanidad estaba en el aire. El jurista escocés McLennan desarrollaba conclusiones parecidas a las de Bachofen cuando tuvo conocimiento del Matriarcado. En 1877, el norteamericano L. M. Morgan, jurista y etnólogo, en su obra Ancient Society le otorgaba a Bachofen el mérito por el descubrimiento del derecho materno. Esto en el ámbito de la ciencia. Hay que remarcar que incluso antes de Bachofen, la reaparición de la mujer fue anticipada por la literatura, la cual — como siempre- presiente las "fuerzas irracionales" que se agitan en el subsuelo social antes de manifestarse a la luz de la consciencia. De hecho, las Madres entran en escena antes de Bachofen, precisamente en 1804 en el teatro de Goethe, en el segundo Fausto, acto I:

Mefistófeles: Mal de mi agrado descubro el sublime misterio. Hay unas diosas augustas que reinan en la soledad. En torno de ellas no hay espacio y menos aún tiempo. Hablar de ellas es un trabajo. Son las MADRES.

Fausto: (sobresaltado) ¡Las Madres!

Mefistófeles: ¿Eso te espanta?

Fausto: ¡Las Madres! ¡Las Madres! [...] ¡Suena eso de un modo tan extraño! [...].

Mefistófeles: Y lo es en realidad. Diosas desconocidas para vosotros los mortales, y que nosotros nunca nombramos de buen talante. Para descubrir su morada, puedes cavar hasta lo más profundo $[\ldots]$ (Fausto, 265).

Y Fausto se hunde en el reino subterráneo de las Madres, donde encuentra a Helena...

Ya antes, después de un viaje en 1857 a Italia, donde quedó pasmado frente a las necrópolis de la Antigüedad, Bachofen había publicado El simbolismo funerario de los antiguos (1859). En ese mismo año escribe a su amigo italiano Agostino Gervasio para anticiparle su futuro proyecto de investigación sobre un tema "nunca antes tratado": "Qué cosa más sorprendente —es- 
cribe en francés - que ver a la mujer de los primeros años de la historia humana ocupar el rango, la posición que un desarrollo más avanzado del género humano ha conferido irrevocablemente a los seres de nuestro sexo masculino", añadiendo que el derecho materno no había sido un fenómeno aislado de un pueblo o de determinados pueblos:

[...] sino lo propio de un determinado estadio de la civilización que, por la similitud y la regularidad de comportamiento de toda la naturaleza humana, no puede ser reducido o limitado a un solo grupo de poblaciones afines. Por lo tanto, es mucho más importante penetrar en la unidad interna de la concepción fundamental, en lugar de notar las similitudes entre cada una de sus manifestaciones.

El "viajero en pantuflas", como se autodenomina, fue el primer estudioso en penetrar en ese terreno virgen que, como se dijo, exploró con erudición impresionante.

Bachofen no se limita al área mediterránea de los primordios: amplía su interés a Egipto, Etiopía, Libia y Asia, llegando inclusive al imperio Inca. Su punto de partida es Licia, a la que se refieren los testimonios más explícitos y exhaustivos, como los de Heródoto y Nicolás de Damasco. Ambos describen los usos y las costumbres de los licios que, como los cretenses de quienes descendían, honraban más a las mujeres que a los hombres, tomaban el nombre de la madre y no del padre, y trasmitían la herencia a las hijas y no a los hijos. Heráclides del Ponto (De rebus publicis), Apolodoro (Bibliotheca) y Plutarco (Historias) confirman que los licios desde la Antigüedad eran gobernados por las mujeres y no tenían leyes escritas, sino sólo costumbres; a esos testimonios Bachofen añade el de otros historiadores. En fin: nombre, soberanía y bienes hereditarios se transmitían por la línea materna. Para confirmar la primacía de la mujer, el estudioso recurre también a los restos arqueológicos: al alto porcentaje de las estatuillas neolíticas representantes de la Gran Ma- 
dre, que supera con mucho en número a la figura masculina. Cabe señalar que la existencia del derecho materno está cuestionada por muchas feministas y por la estudiosa italiana Eva Cantarella.

La publicación del Matriarcado no tuvo una repercusión favorable en el público de la época, salvo admiradores excepcionales, como Marx, Engels (éste lo cita en El origen de la familia, de la propiedad privada y del Estado) y Nietzsche, quien de 1869 a 1876 enseñó filología clásica en Basilea y conocía la obra de Bachofen (está registrado en la biblioteca de esa ciudad que el filósofo tomó prestado en junio de 1871 el Ensayo sobre el simbolismo de los antiguos).

El libro no se tradujo a otros idiomas y recibió abundantes críticas sin que se mencionara a su autor. Las razones de ello fueron sobre todo de orden práctico e ideológico. Por un lado estaba la edición confusa por culpa del tipógrafo, sin subdivisión en capítulos, con las notas integradas en el texto sin cambio de letra, erratas de imprenta - defectos que se repitieron en la segunda edición. Asimismo, como subraya Furio Jesi, los temas del libro llegaban a "proporciones hipertróficas y maniáticas", y es difícil que alguien lo haya leído por entero; inclusive, es probable que sus pocos admiradores hayan hecho una lectura antológica del texto.

Por el otro lado, no sólo los defectos de la edición impidieron la difusión del libro. También influyó la hostilidad del ambiente académico, el cual juzgó a Bachofen como un diletante que no tenía los papeles en regla fuera de su especialidad, el Derecho Romano. Fue muy criticado su uso de símbolos y mitos que, como se ha visto, utilizaba como fuentes históricas fehacientes, sin hacer distinción entre mito e historia. Para él, el mito es espejo fiel de todos los periodos de la historia de los pueblos primigenios, manifestación del modo de pensar originario, formulado en la lengua primordial. 
Igualmente fue censurada su libertad para acudir a varias disciplinas y vincular el derecho con otras visiones de la vida. Bachofen no se inmutó y a su vez señaló las delimitaciones convencionales entre las ciencias, rechazando la tendencia a aislar cada disciplina y la historia de cada pueblo en casillas separadas; se pretende, objetó, profundizar las investigaciones limitando su campo de estudio a la especialización, método que sólo lleva a una concepción superficial, carente de toda espiritualidad: no se puede conocer una civilización si se observa aislada.

En pocas palabras, Bachofen sostiene y utiliza el método interdisciplinario y comparativo que hoy resulta indispensable. Más fuerte fue el rechazo ideológico debido a la tesis novedosa y revolucionaria de Bachofen, que ponía en crisis los presupuestos histórico-ideológicos de la familia, de la propiedad privada y por ende del patriarcado. De hecho, el descubrimiento de una ginecocracia, de un reino de las Madres en los albores de la historia de la humanidad, ponía en tela de juicio la continuidad y la persistencia de la soberanía del derecho paterno, su inamovilidad, y comprobaba así su carácter transitorio.

Bachofen compara matriarcado y patriarcado, su enfrentamiento y su alternancia, las diferencias entre las normas de comportamiento de las dos formas de organización social: la primera natural y consuetudinaria, la segunda civil y positiva, escrita. La etapa primordial, bajo el dominio de la mujer, había mantenido la sumisión a la naturaleza, vivida como la Gran Madre procreadora y nutritiva, el politeísmo, la veneración de los dioses, de los vínculos sagrados de la sangre y el suelo, el culto de los muertos, la comunidad de los bienes, la igualdad social, la fraternidad universal y, por tanto, la estabilidad y la paz (en esa etapa no se conocieron conflictos internos ni guerras).

Bachofen evoca con acentos nostálgicos la era materna, "poesía de la historia", cuando el vínculo amoroso madre-niño era más estrecho. En los estadios más profundos y oscuros de la 
existencia humana, dice Bachofen, el amor entre la madre y el recién nacido de su cuerpo representa el punto más luminoso de la vida, el único claror en la tiniebla moral, la sola beatitud en la profunda miseria. Del principio de la maternidad generadora brota la fraternidad de todos los hombres, cuya consciencia y cuya legitimidad declinan cuando se desarrolla la noción de paternidad. Y añade que en el principio materno se basa el de libertad e igualdad universal que reconocemos como rasgo fundamental de los pueblos ginecocráticos.

Sin embargo, no obstante sus acentos nostálgicos, el autor no deja de ser un burgués conservador, asertor de la superioridad jurídica y sexual del patriarcado. De hecho, cuando a los cincuenta años y después de la muerte de su madre (mujer culta y brillante, a quien Bachofen dedicó su Matriarcado) se casó con una bellísima joven de veinte años y, como él mismo escribe en sus memorias, vivió con ella un ménage gobernado "según criterios imperialistas", es decir, bajo las leyes del patriarcado. Bachofen no cuestiona la superioridad del derecho paterno ni plantea la necesidad de una recomposición o de una reinserción de la mujer en el sistema patriarcal, como lo harán otros pensadores en el siglo xx. El psicoanalista Erich Fromm subrayará la profunda contradicción en semejante proceder, afirmando:

Es evidente que existe una profunda contradicción entre el Bachofen que admira la democracia ginecocrática y el aristocrático Bachofen de Basilea, que se opuso a la emancipación política de su mujer y dijo: "Por la fuerza de las circunstancias, la democracia siempre allana el camino de la tiranía; mi ideal es una república gobernada, no por los muchos, sino por los mejores ciudadanos". Es una contradicción que aflora en varios planos distintos. En el plano filosófico, es el protestante e idealista creyente contra el romántico; y el filósofo dialéctico contra el metafísico naturalista. En el plano social político, es el antidemócrata contra el admirador de una estructura social comunista-democrática. En el plano de lo moral protestante- 
burguesa contra el defensor de una sociedad en que reine la libertad sexual en lugar del matrimonio monógamo (Fromm, Crisis del psicoanálisis, 142-143).

Hay que precisar que el heterismo (promiscuidad sexual) primitivo y brutal supuestamente atribuido por Bachofen a la mujer no tiene fundamento. De su lectura no se saca ninguna conclusión de que él atribuya los excesos sexuales a la mujer o a la ginecocracia. El estudioso habla, más bien, de un estadio primordial antes de la transición a la autoridad materna, de un estadio "inferior" de la existencia humana, que habría sido dominado por la violencia y la fuerza bruta del hombre, durante el cual la promiscuidad fue absoluta, desenfrenada, y el acoplamiento se realizaba en público, delante de todos. Bastaba que el hombre plantara su bastón frente a la casa de la mujer (el bastón clavado en el terreno era el símbolo del acto sexual) para unirse con ella.

Gradualmente, bajo la influencia de la mujer que se rebeló con obstinación y astucia al abuso del hombre, esa promiscuidad se transformó en matrimonio monogámico. Las jóvenes solteras eran libres de unirse con quien quisieran, pero una vez casadas debían, así como los hombres, guardar fidelidad al matrimonio; el adulterio, también el del hombre, era castigado con la muerte. El primer paso a la ginecocracia se origina, pues, en la resistencia femenina contra la condición animal que la fuerza bruta desenfrenada del hombre le imponía.

Según Bachofen, la influencia de la mujer en el niño y en el hombre hubiera sido imposible en condiciones de promiscuidad sexual, y por tanto fue posible sólo en el ámbito del matrimonio monogámico bajo Deméter. El estudioso suizo insiste en la función educadora y civilizadora de la mujer en esa etapa de la humanidad; a ella le fue dado domeñar las armas y el fuego y apaciguar a los hombres en contienda, de ahí su carácter sagrado e intangibilidad. En este sentido, la ginecocracia fue una 
etapa necesaria en la educación de la humanidad. En el capítulo "Orcómenos y los Minios", Bachofen indica que fue la mujer quien llevó la elevación del género humano hacia una más alta norma de vida y de civilización; en las mujeres nació por primera vez el deseo de ordenar las condiciones de vida, así como la necesidad y la inteligencia de una religiosidad más pura.

Ahora bien, es difícil conciliar esta imagen de la mujer civilizadora con la adoración femenina a Dionisos, dios de las mujeres, con el que el autor se entretiene en el mismo capítulo "Orcómenos y los Minios". Ningún otro culto como el báquico, dice Bachofen, ejerció una influencia tan profunda en la estructura de la vida de los pueblos antiguos, ningún otro culto contribuyó de manera tan tajante en la evolución del espíritu femenino; en ningún otro los aspectos más nobles y al mismo tiempo más bajos de los que es capaz el ánimo femenino aparecen tan interconectados; en ningún otro campo encontramos tantas aristas sublimes y degradantes.

Bachofen hace énfasis en los estadios intermedios y alternos entre el matriarcado y el patriarcado, en los que lo antiguo y lo nuevo se encuentran lado a lado: fases intermedias de transición entre la comunidad sexual, que respondía a preceptos religiosos del principio materno, según los cuales el matrimonio era transgresivo de las leyes de la naturaleza y el patriarcado. En estas fases se configuraría una relación de antagonismo abierto entre los dos sexos, durante la cual aparecería Dionisos, el dios oriental llegado a Grecia a través de Tracia y que desempeña un papel de gran importancia.

El culto báquico surge con la derrota del movimiento de las amazonas - reconocido generalmente como hecho histórico y no como ficción mitológica-, grupo de mujeres extremistas definido por Bachofen como una "degeneración de la ginecocracia", quienes para conservar su supremacía se sublevaron contra el abuso masculino, pasando de la hostilidad hacia el dios asiático contrario al amazonismo a su adoración. En las fies- 
tas en honor a Dionisos, las mujeres caen en un estado tal de ebriedad física y psíquica, furor y locura (manía), desenfreno orgiástico y trance colectivo que, poseídas por el dios, pierden la conciencia de sí mismas. Ese estado de ánimo quedó representado por Eurípides en Las Bacantes; Ágave, cegada por el frenesí, llega inclusive a descuartizar a su hijo Penteo, opositor de Dionisos.

Bachofen recurre al testimonio de Plutarco, quien en sus Quaestiones grecae narra cómo en Beocia, durante una fiesta dionisíaca, Ipaso había sido despedazado por su propia madre. En "Orcómenos y los Minios", el estudioso subraya la afinidad entre Dionisios y la índole natural de la mujer, la ambivalencia o duplicidad del dios del desenfreno de los sentidos, la desinhibición y la libertad de toda represión. En ese mismo capítulo compara a Dionisos, el dios de la metamorfosis, redentor y liberador de los dolores del hombre griego, con Apolo, el dios luminoso, sereno, eternamente igual y "tranquilizador", comparación que nos remite automáticamente a Nietzsche en $\mathrm{El}$ nacimiento de la tragedia y a su célebre distinción entre lo apolíneo y lo dionisiaco.

Es probable que Nietzsche, en su estancia en Basilea, de donde iba a menudo a Tribschen para visitar a Wagner, haya frecuentado también a Bachofen, y del contacto con su obra (que, como apuntamos, había leído) y de las conversaciones con Wagner (a quien dedica el libro) haya surgido la chispa que lo llevó a ahondar en esa distinción. Sin embargo, Nietzsche va más allá de Bachofen: Apolo y Dionisos son dos fuerzas, dos impulsos opuestos de la naturaleza que se integran, en una relación dialéctica, en la obra artística. Apolo, el dios solar de la individuación, no puede vivir sin Dionisos, el dios de la ebriedad que lleva a la liberación del yo individual y a su aniquilamiento en el yo colectivo.

El viraje de la ginecocracia al patriarcado, interrumpido, ya se vio, por estadios intermedios como la lucha amazónica, fue 
lento, gradual y lleno de contrastes; en esos estadios lo antiguo y lo nuevo coexistieron. La supremacía del matriarcado duró milenios, pero tuvo que ceder frente al patriarcado después de una larga interiorización de la imagen paterna, que terminó imponiéndose y desplazando al principio materno. El padre se afirmó después de graves contrastes con el matriarcado, comprobados por los mitos que hablan de cruentas luchas contra serpientes, dragones y monstruos, todos símbolos primigenios del elemento materno. Cesa así la dependencia ciega hacia la madre, cuya imago, hay que subrayarlo, es ambivalente y ofrece dos aspectos, uno constructivo y otro destructivo: la madre buena, fuente de seguridad, que da calor, abriga y alimenta, pero también la madre mala con su riesgo de opresión, debido a la cristalización de su función de nodriza; se sabe que la fijación en la madre, símbolo del inconsciente, amenaza con paralizar el desarrollo del yo, su autonomía. El triunfo del principio paterno, dice Bachofen, implica la emancipación de las manifestaciones de la naturaleza, la elevación de la existencia humana por encima de la vida corpórea, material; con ello el hombre rompe las cadenas del telurismo.

Bachofen estudia el conflicto y la alternancia entre las dos fuerzas opuestas recurriendo no sólo a fuentes históricas, sino también a las tragedias de Esquilo (525-426 a. C.) y de Eurípides. La última parte de la trilogía de la Orestíada de Esquilo, "Las Euménides", documenta el conflicto entre las dos fuerzas. En la primera parte, Agamenón regresa a Argos después de diez años de guerra contra Troya; su esposa Clitemnestra, que en esos años había sido amante de Egisto, lo acoge con festejos para luego asesinarlo. Orestes, el hijo de ambos, para vengar al padre mata a la madre. Por ello, las Euménides, guardianas del orden materno todavía vigente, intervienen para enjuiciarlo, y cuando él les pregunta por qué no habían castigado a la asesina, ellas contestan: "No era consanguínea del hombre al que mató". Matar a la madre, con la que se tienen vínculos de 
consanguinidad, era la peor trasgresión de las normas inviolables del derecho materno, cualquiera que hubiese sido su motivación. Sin embargo, las Euménides terminan doblegándose a Atenea y Apolo, es decir, a los dioses del principio paterno.

"Yo no tuve madre que me generara - dice la diosa Atenea, nacida de la cabeza de Zeus olímpico-, y propendo por el hombre". Apolo, el dios solar, va más allá de Atenea y niega cualquier derecho a la madre: "No es la que llaman madre la que engendra un hijo, sino que es sólo la nodriza del embrión recién sembrado" (Esquilo, Tragedias, 523). Por lo tanto, Apolo y Atenea llaman a un proceso público (el primer proceso de la historia, observa Bachofen) y a una votación que absuelve a Orestes. El diálogo entre las Euménides y los dos dioses abre un debate acerca de la mujer que prevalecerá durante milenios.

Bachofen acude también a Eurípides (¿480?-406 a. C.) quien en su Medea enfrenta el conflicto entre el viejo y el nuevo principio de vida y lo simboliza en el mito de los argonautas: la relación entre el héroe Jasón y Medea y el inicial connubio amoroso entre los dos. El mito de los Argonautas registra claramente el choque entre el mundo asiático, gobernado por el derecho de las madres, y el mundo griego, sometido al principio paterno. El héroe griego Jasón se dirige con sus compañeros en la nave Argos a la isla de Cólquida, en busca del vellocino de oro. La asiática Medea, hija del rey de Cólquida, se enamora del él y lo ayuda con sus artes mágicas a apoderarse del vellocino; llega a matar a su propio hermano para defender al héroe y lo sigue a Grecia como su esposa. Una vez en su patria, Jasón la repudia para casarse con Créila, hija del rey de Corinto. Traicionada, Medea se venga, y con su poder mágico mata a Créila y a su padre; después da muerte a sus propios hijos y huye en un carro tirado por dos dragones.

El ocaso definitivo de la ginecocracia dio inicio a una nueva etapa en la historia de la humanidad, la del patriarcado, etapa necesaria porque sin intervención activa en la naturaleza el gé- 
nero humano no habría podido sobrevivir. El humano es un animal biológicamente desprovisto. La ciencia y la técnica introducidas por el hombre nacieron como "remedio" a la insuficiencia biológica de un ser que, al contrario de los animales que nacen oportunamente abastecidos de todo por la naturaleza, es incompleto: el humano nace desnudo, descalzo, indefenso. Gracias a las construcciones técnicas, a los artefactos, la humanidad ha logrado "culturalmente" la estabilidad que el animal posee por naturaleza; la técnica ha seguido al ser humano desde los primordios (Prometeo).

Con la victoria del patriarcado empieza el desarrollo arriesgado y unilateral del espíritu masculino, no equilibrado por el mundo de la psique materna. Bajo el orden paterno, el principio de racionalidad modifica por completo la naturaleza, que se volverá objeto de la intervención y de la explotación en exceso del hombre, hasta la catástrofe ecológica que hoy amenaza su supervivencia. La naturaleza, despojada de sus calidades metafísicas, será reducida a objeto de utilidad y de cálculo, y el sistema social se verá invertido.

Al universalismo del principio materno sigue el individualismo; a la igualdad, la diversidad y la discriminación social; a la libertad sexual propia del derecho materno, la moral represiva de la sexualidad; a la preeminencia del lado izquierdo, el lado derecho; al politeísmo religioso de la Madre, el monoteísmo paterno autoritario (la familia, la propiedad privada y el Estado); a la paz y la justicia, la violencia y la guerra. En fin, Bachofen dirá que la unidad de la masa se disgrega, y la realidad indiferenciada será superada por el principio de separación ("Preámbulo e introducción"). La división del trabajo, que había empezado en la Edad de Bronce y de Hierro, alejará a la mujer de cualquier actividad fuera del ámbito de la reproducción. Ella, que había introducido la agricultura, la cerámica, el tejido, se limita ahora a criar a sus hijos. Su rol como madre se invierte: de protectora pasa a ser madre "protegida" por el hijo. 
Como dice Benjamin, la transición del derecho materno al derecho paterno estará documentada en el siglo xx por los estudios científicos de etnografía y antropología sobre las sociedades pertenecientes aún al estadio salvaje.

La madre, "materia-tierra-tinieblas-luna", y el padre, "espíritu-cielo-luz-sol", van a ser estereotipos para siempre. La mujer pierde su rol protagónico y queda encuadrada en el sistema patriarcal como un apéndice bajo la tutela del hombre. Da inicio la misoginia del mundo occidental, teorizada por Aristóteles, a la que sucederá la satanización de la mujer por parte de la Iglesia católica. El antifeminismo acompañará a la mujer durante centurias, hasta finales del siglo XIx. Salvo excepciones, escritores y poetas manifestarán desprecio o ninguneo hacia ella. Un ejemplo es la Physiologie du mariage, de Balzac, en la que se la condena así: "El destino de la mujer y su gloria única consisten hacer latir el corazón de los hombres" (Balzac apud Beauvoir, Segundo sexo, 102). Asimismo, el novelista francés pensaba que "hay que negarle la instrucción y la cultura, prohibirle todo cuanto podría permitirle desarrollar su individualidad, imponerle ropas incómodas, animarla para que siga un régimen conducente a la anemia" (102).Y él añade que "la mujer casada es una esclava a quien hay que saber sentar en un trono" (102103).

La mujer permanecerá definitivamente mutilada hasta principios del siglo xx, cuando despierta la autoconciencia femenina, que se manifiesta en la realidad histórica, con las reivindicaciones de las sufragistas en Inglaterra — que a menudo terminan en la cárcel. El movimiento llega de arriba, de la clase aristocrática y la alta burguesía para propagarse hacia abajo y por todo Occidente.

Si bien la mujer desaparece de la historia, su imago, sin embargo, permanece relegada en el inconsciente colectivo, y como observa justamente Melanie Klein, es probable que la sucesiva conquista de la naturaleza y su explotación por parte del hom- 
bre hayan sido vividas por el inconsciente colectivo como una agresión sádica contra la Madre, como un matricidio. De hecho la Gran Madre permanece presente en el historiador Plutarco (¿46?-127 d. C.) —sacerdote en Delfos del templo de Apolo, dios de lo masculino - , quien todavía atribuye a Isis, la Gran Madre egipcia, estas palabras: "Yo soy todo lo que ha sido, lo que es y lo que será, y mi peplo jamás me lo levantó ningún mortal" (Plutarco, Obras, 73). El romano Apuleyo (¿125?-184 d. C.) dedica su Asno de oro a Isis, la Madre de la creación, "el tronco que da origen a las generaciones, la suprema divinidad" (Apuleyo, El asno, 325). Milenios después, la pérdida de la unidad originaria con la naturaleza continuará viviéndose como una mutilación. Hasta el siglo xx la mujer estará condenada, como dice Simone de Beauvoir (Le deuxième sexe), a permanecer encerrada en el mundo de la inmanencia, de las labores fijas y repetitivas del quehacer cotidiano, encarnando sólo el aspecto pasivo, estático e inmutable de la sociedad, mientras que el hombre entra en el mundo de la trascendencia: creador, constructor, proyectado hacia el futuro. ${ }^{2}$ Trascendencia e inmanencia, el espíritu contra la vida, será el lema de los intelectuales del siglo xx (a los que se unió el Mann de Consideraciones de un impolítico); alma-espíritu serán los temas de la filosofía de Ludwig Klages y del poeta Stefan George.

Hemos sintetizado esquemáticamente el contenido del $M a$ triarcado de Bachofen, una obra que ha dado origen a interpretaciones opuestas. El mitólogo Furio Jesi, estudioso de la obra bachofeniana, la critica a pesar de reconocer la objetividad de su descubrimiento histórico. Según Jesi, Bachofen sería un anticuario que acumula objetos originales como prueba de un material demasiado heterogéneo. No obstante, la obra de Bachofen tuvo amplia influencia en las corrientes culturales más diver-

${ }^{2}$ Dicho sea de paso, Simone de Beauvoir nombra sólo dos veces a Bachofen, estropeando su nombre - Brachoffen - y liquidándolo en una breve nota como un autor ya superado por la moderna sociología. 
sas, desde la izquierda marxista y anarquista del siglo XIX hasta el psicoanálisis, y el movimiento feminista, cuando despierta en la realidad histórica la autoconciencia femenina y empieza la lucha de las mujeres por su emancipación; influirá también en la cultura de derecha del siglo xx y en los nazis.

Es importante recalcar que la rebeldía femenina al autoritarismo masculino está anticipada por Ibsen en su Casa de muñecas (1879). Después de ocho años de matrimonio, la protagonista Nora se rebela ante el esposo, quien la trata y la mima como a una niña ("mi alondra", "mi ardilla", "mi pajarito"), pero a la primera dificultad la critica duramente; ella abandona el techo conyugal junto a sus hijos.

La posición con respecto al movimiento feminista del siglo xx será de apoyo o de rechazo. En 1903, un poeta de aguda sensibilidad como Rainer María Rilke advierte la necesidad de una integración de los dos géneros, y en una carta al joven Franz Xavier Kappus sostiene que "la gran renovación del mundo quizá consista en que el hombre y la mujer, liberados de todos los sentires erróneos y desganas, no se buscarán como opuestos, sino como hermanos y vecinos, y se reunirán como personas" (Rilke, Cartas, 48).

Sigmund Freud, al contrario, sostendrá la visión patriarcal y verá en la transición de la madre al padre una victoria de la espiritualidad sobre la sensualidad, y por lo tanto un progreso cultural. De Freud diverge Theodor W. Adorno en su Minima moralia de 1945 (subtitulado significativamente Reflexiones desde la vida dañada), que critica la escisión naturaleza-hombre, sosteniendo que la mujer es el efecto del látigo del hombre (Nietzsche había dicho: "Si vas con la mujer, no olvides el látigo"). En el aforismo 59, Adorno comenta:

El carácter femenino y el ideal de la feminidad conforme al cual se halla moldeado, son producto de la sociedad masculina. [...] Dondequiera que tal naturaleza pretende ser humana, la 
sociedad masculina aplica con plena soberanía en las mujeres su propio correctivo, mostrándose con su restricción como un maestro riguroso. El carácter femenino es una copia del "positivo" de la dominación. Así resulta tan mala como ésta. Lo que dentro del sistemático enmascaramiento burgués se denomina en general naturaleza, es simplemente la cicatriz que deja la mutilación producida por la sociedad. Si es cierto que el teorema psicoanalítico según el cual las mujeres viven su constitución psíquica como la consecuencia de una castración, éstas tienen en su neurosis una vislumbre de la verdad (Minima, 99-100).

En el mismo libro Adorno se aleja de Freud y desaprueba lo contradictorio de su posición. Por un lado, Freud critica la ideología burguesa, es decir, la condena del instinto; por otro lado, adhiere a esa condena en nombre de la cultura. Critica la renuncia, el sacrificio del instinto contrario a la realidad, y al mismo tiempo exalta ese sacrificio como sublimación promotora de cultura. Freud, concluye Adorno, está a medio camino entre el deseo de una emancipación de los oprimidos y la apología de su supresión.

Después de la Segunda Guerra Mundial varios estudiosos toman su punto de partida del Matriarcado de Bachofen: Erich Neumann (Historia de los orígenes de la conciencia, 1949 y La Gran Madre, 1956); Erich Fromm (La crisis del psicoanálisis, 1970); Franz Baumer (La Grande Madre. Scenari da un mondo mitico, 1995).

Particularmente interesante es un libro del psicoanalista francés Gérard Mendel, quien explica la rebelión de las generaciones de 1968 como una oposición a la opresión del mundo moderno tiránico y autocastrador; una rebelión contra el poder paterno que habría causado un "trastorno de las alianzas": la alianza con la madre vengadora y el rechazo de la racionalidad, así como nuevas formas místicas, nihilismo, rechazo psicopático de la realidad. El triunfo del padre sobre el elemento femenino llega a la autodestrucción. 
De hecho, afirma Mendel, la destrucción ecológica es también la gran metáfora de la destrucción del elemento femenino, de la gran Madre tierra. ¿Qué se necesitaría para evitar la destrucción?, se pregunta el autor. Una guerra de las amazonas en una nueva versión. El mundo femenino debería unirse y detener la caída en el abismo en el que ya nos encontramos, antes de llegar hasta el fondo. Está en juego el destino de la humanidad. La mujer se ha erigido contra el hombre para declarar sus derechos de igualdad, pero entre el modelo masculino. Sin un proyecto revolucionario de ese mundo, ella misma contribuirá a la destrucción de la humanidad.

Estos autores insisten en que el riesgo de la humanidad consiste hoy, en parte, en el desarrollo consciente, unilateral del patriarcado, no equilibrado por el mundo psíquico arquetípico de lo femenino; insisten en la urgencia del desarrollo de cada individuo hacia la totalidad psíquica y la integración de los dos principios, el paterno y el materno, que debería ser el ideal educativo del futuro: sólo este desarrollo integral hará posible una vida fecunda de la comunidad.

\section{REFERENCIAS}

Adorno, Theodor Wiesengrund, Minima Moralia. Reflexiones desde la vida dañada. Obra completa 4, Madrid, Akal, 2006.

Apuleyo, El asno de oro, trad. Lisandro Rubio Fernández, Madrid, Gredos, 1995.

B ACHOFEn, Johann Jakob, Il matriarcato, 2 tomos, Torino, Einaudi, 1988.

BAUMER, Franz, La Grande Madre, Génova, ECIG, 1995.

Benjamin, Walter, Obras, Libro II / vol. 1, Madrid, Adaba, 2007.

Beauvorr, Simone de, El segundo sexo, Buenos Aires, Sudamericana, 1999.

EuRIPIDEs, Tragedias: Medea, Las Bacantes, Ifigenia en Aúlide, Barcelona, Bruguera, 1973. 
EsQuilo, Tragedias, trad. Bernardo Perea Morales, Madrid, Gredos, 2007.

Fromm, Erich, La crisis del psicoanálisis, México, Paidós, 1995.

Goethe, Johann Wolfang, Fausto, México, Universidad Nacional Autónoma de México, 1924.

IBSEn, Henrik, Casa de muñecas, Madrid, Cátedra, 1999.

Mendel, Gerard, La rebelión contra el padre, Barcelona, Península, 1968.

Neumann, Erich, Storia delle origini della coscienza, Roma, Astrolabio, 1978.

—_ La Grande Madre, Roma, Astrolabio, 1981.

Plutarco, Obras Morales y de costumbres (Moralia) VI, Madrid, Gredos, 1995.

RILKe, Rainer María, Cartas a un joven poeta, Madrid, Alianza, 2001. 